Article

\title{
External Unilateral Fixator of Own Design for the Treatment of Selected Mandibular Fractures in Horses
}

\author{
Bernard Turek ${ }^{1, * \mathbb{D}}$, Olga Drewnowska ${ }^{1, *}$ and Marcin Kapłan ${ }^{2}$ \\ 1 Department of Large Animal Diseases with Clinic, Faculty of Veterinary Medicine, \\ Warsaw University of Life Sciences, Nowoursynowska 166, 02-787 Warsaw, Poland \\ 2 Animal Care Kaplan, Horoszki Duże 56, 08-221 Sarnaki, Poland \\ * Correspondence: bernardturek@gmail.com (B.T.); vet.olgadrewnowska@gmail.com (O.D.); \\ Tel.: +48-604-247-640 (B.T.)
}

Received: 9 May 2019; Accepted: 26 June 2019; Published: 28 June 2019

\begin{abstract}
Most of the mandibular fractures occur as a result of accidents, kicks, or falls. The treatment of fractures located in the incisor region is quite successful with the use of the wiring method. Fractures that occur within the body of the mandible are more complicated. Some of them are open and infected and involve the cheek teeth, which makes treatment quite challenging. In these cases, using bone plates mounted directly on the bone would constitute poor technique. External skeletal fixators can be a good alternative for treatment of complicated fractures. In this article we present the construction and the possible use of a unilateral external fixator dedicated for the treatment of mandibular body fractures. The fixator consists of one rod having a diameter of $8 \mathrm{~mm}$ and a length of $20 \mathrm{~cm}$, four booms, four connectors, and four self-threading apex pins with a diameter of $6 \mathrm{~mm}$. Stainless steel was used in the production of the fixator. The device has been successfully used for the treatment of open mandible fractures. The stabilizer is light and is small in size, simple to use, and easily assembled and disassembled. It can be adjusted in three planes.
\end{abstract}

Keywords: horses; fractures; osteosynthesis; external fixation; mandible

\section{Introduction}

\subsection{Background}

Treatment of some bone fracture cases in horses is difficult. Due to a large variety of bones and their different sizes and shapes, there is no universal method that could be used in treatment of fractures. Each bone requires an individual approach. Complex fractures of long bones that consist of many bone fragments often lead to euthanasia. Open fractures pose a greater challenge as they often become contaminated and infected. Fractures need to be stabilised well in order to achieve bone union. However, using plates fixed directly on a bone in such case would constitute poor practice. External fixators could become an acceptable solution. The following types of fixators may be distinguished: Unilateral, bilateral, trilateral, quadrilateral, semi-circular, and circular. Each of them may be used to treat different fractures depending on its location and pattern. Unilateral fixators provide the least stabilisation, but they are the easiest to use and do not disturb normal everyday functioning of an animal. The others are a lot more complex. This is why unilateral fixators stabilise bone fragments to a greater extent. A very extensive structure fixated externally, however, interferes with the normal functioning of a horse.

Mandibular fractures are the most common among all skull fractures [1-5]. Most of them result from an injury, such as hitting an obstacle or being kicked by another horse, or when horses play with metal objects in the stable. Other possible causes include iatrogenic damage during tooth extraction or secondary damage due to ongoing disease processes, such as osteosarcoma or osteomyelitis [6]. 
A mandibular fracture can create many different clinical signs, like dysphagia, pain, malalignment of incisors, displacement of teeth in the arcade, instability of the jaw, crepitation, excessive salivation, swelling, and enlargement of the affected region. Some horses with displaced fractures are not able to eat and drink. In order to establish a precise diagnosis, it is very important to perform clinical and radiological examinations. In very complicated cases, CT exam can also be helpful in considering the proper methods of treatment.

On the basis of anatomical location, fractures are classified as fractures of the incisive area, interdental space, horizontal ramus, and the vertical part of the jaw, the most common being fractures of the incisive area. Only stable and non-displaced fractures can be considered for conservative treatment [5,7]. Fractures of the mandibular body pose the greatest challenge to a practitioner among all mandibular fractures. The majority of them are opened, which makes their treatment much more difficult $[3,8,9]$. Depending on location and fracture configuration, the following surgical methods can be used: Wire loops in the oral cavity, wire loops enforced with synthetic materials, screws, U-shaped plate placed in the oral cavity, transmandibular Steinmann pins, steel plates (DCP, dynamic compression plates; LCP, locking compression plates) [10-16]. The use of DCP or LCP plates fixated directly on the bone at the ventrolateral site of the jaw provide the best stabilisation [17] but for opened infected fractures, this is not recommended. For the fixation of some fractures, only screws were needed. Biodegradable magnesium alloys can also be considered in the future [18]. Fractures of incisive bone, although being opened, are successfully treated using wire loops, which stabilise the bone to a required extent $[1-3,10-12,16]$. External fixators are a separate method. They are especially indicated for the treatment of open fractures. Sometimes, for successful treatment, it is necessary to use a combination of a few methods [16,19].

The use of external fixators in the treatment of selected fractures, mainly animal limb bones, has been described since the 1930s [20]. External skeletal fixation is quite popular for the treatment of fractures in cattle [21]. The authors of this article present a new external skeletal fixator for the treatment of mid-diaphyseal fractures of the third metacarpal bone in horses [22,23]. The fixator presented in this manuscript is part of the design for the treatment of MC III bone [22,23]. The other authors described treatment of 16 cases with mandibular fractures using external fixation [5]. On the other hand, Swiss scientists presented treatment of nine fractures in horses using unilateral pinless external fixators (PEF) in 2010 [8]. Several years before using it in horses, PEFs were used in treatment of mandibular fractures in cows [9]. Apart from the last one (PEF), no more information on a typical device intended for treatment of fractures of the mandibular body in horses is available in current literature to the authors' knowledge.

\subsection{Objectives}

The main aim of the article is to present a novel idea involving the construction of a unilateral external fixator of our design intended for the treatment of selected fractures of mandibular body in horses (Figure 1). Advantages and disadvantages of the fixator are also presented.

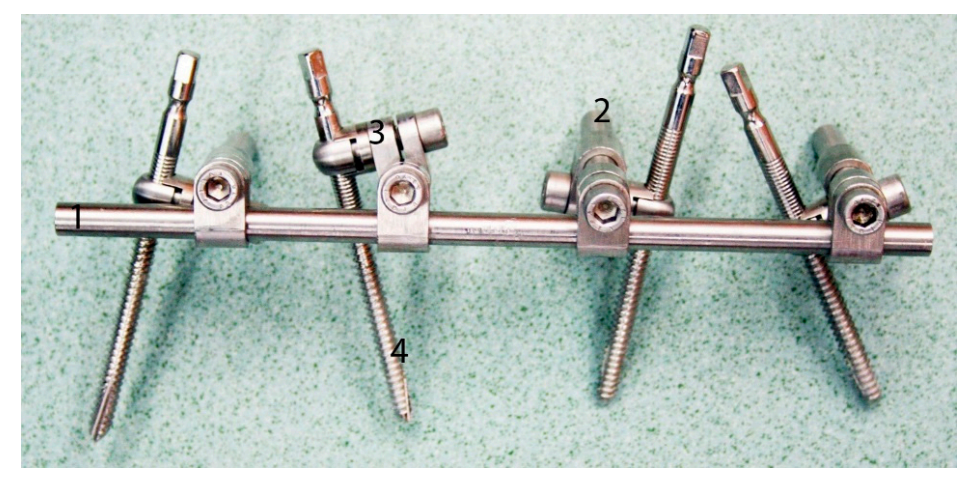

Figure 1. Mounted fixator and its parts; (1) Main rod, (2) arms, (3) pin coupling, (4) pins. 


\section{Materials and Methods}

\subsection{Structure of the Fixator}

The unilateral external fixator of our design (Figure 1) consists of the following elements: (1) Rod with a diameter of $8 \mathrm{~mm}$ and length of $20 \mathrm{~cm}, 4$ arms, 4 pin couplings, and 4 pins. An arm (Figure 2) is made of a rod with a diameter of $8 \mathrm{~mm}$ and a length of $50 \mathrm{~mm}$ terminated on one side with a cone fixed using a clamp with M5 screw, clamp, and screw.

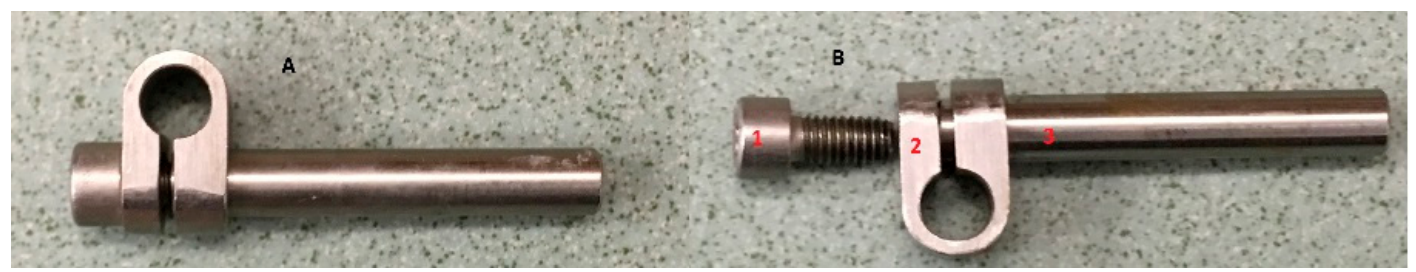

Figure 2. Arm and its elements: (A) Mounted arm; (B) parts of the arm; (1). M5 screw, (2) clamp, (3) rod.

A pin coupled with the main rod (Figure 3) consists of four elements: Stem, sleeve, clamp, and screw.

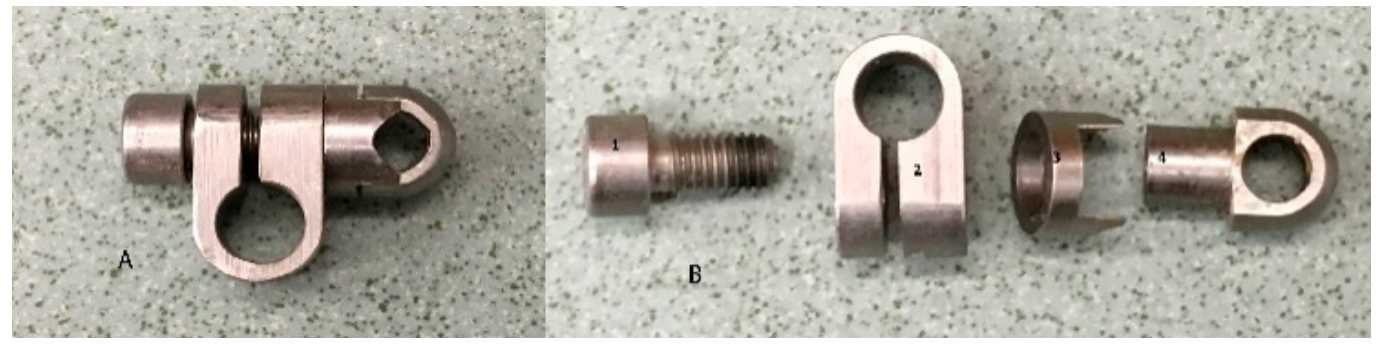

Figure 3. Pin coupling and its elements: (A) Mounted pin coupling; (B) pin coupling elements; (1) M5 screw, (2) clamp, (3) sleeve, (4) stem.

Four apex pins (Figure 4) are used for the fixation.

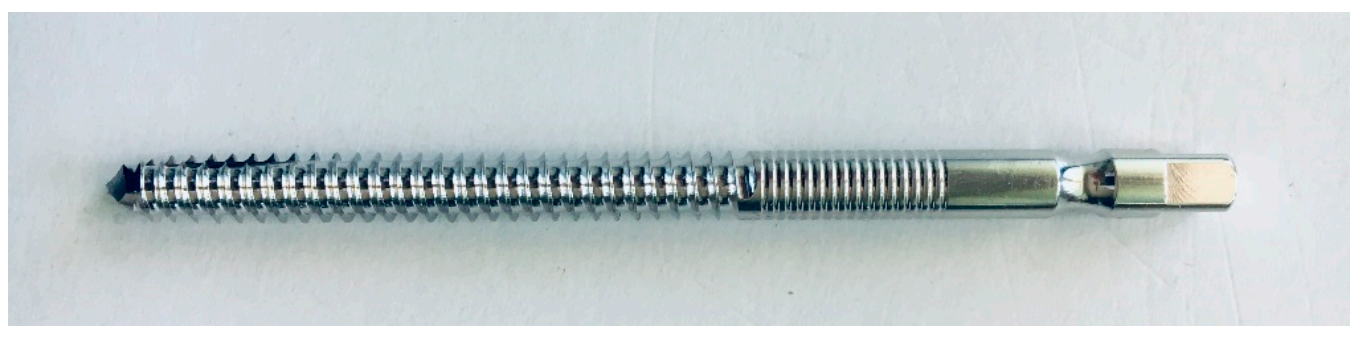

Figure 4. Apex pin with a diameter of $6 \mathrm{~mm}$.

\subsection{Instruments Used for Application}

Instruments that were needed to mount the fixator and establish fixation are as follows: (1) Drill with changeable attachments, (2) drill bit with a diameter of $4.5 \mathrm{~mm}$ and a set of assembly tools (pin inserter, bent and straight hex key used to mount clamps, and other fixator elements) (Figure 5). 


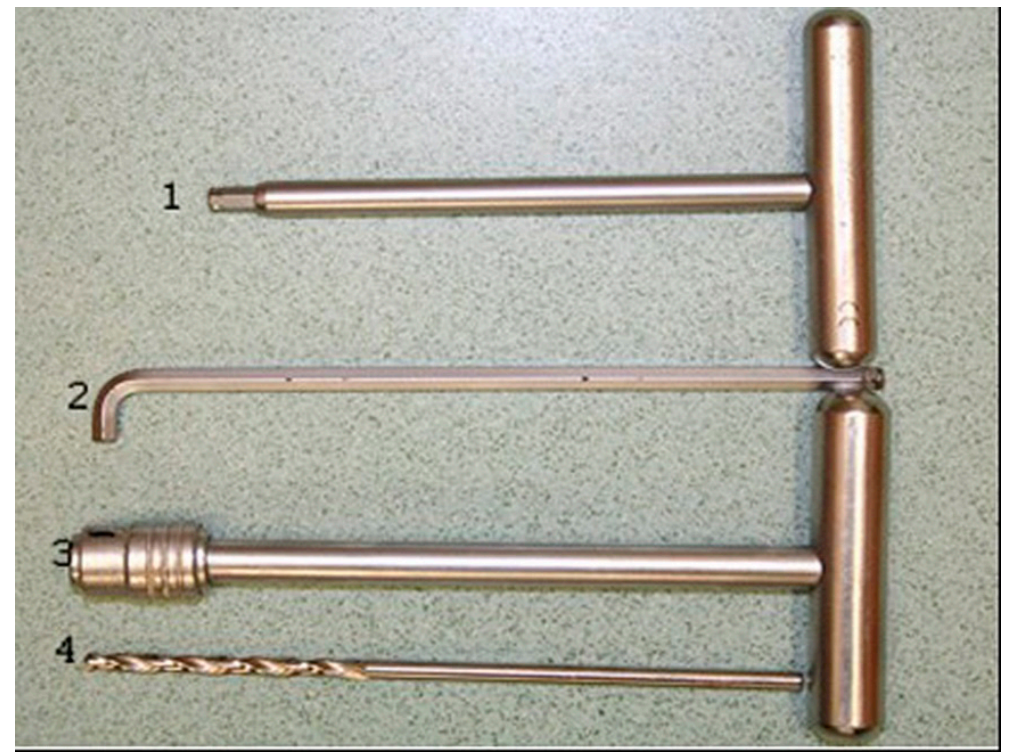

Figure 5. Assembly tools and drill bit; (1) Straight hex key, (2) bent hex key, (3) pin inserter, (4) drill bit with a diameter of $4.5 \mathrm{~mm}$.

The fixator consists of four arms placed on the main rod with previously mounted pin couplings. Such design allows the fixation of bones with implants inserted into the bone beforehand.

\subsection{Surgical Technique Used for Application of the External Skeletal Fixator}

The external skeletal fixator can be applied to the affected bone under general anesthesia or in some calm horses with a combination of sedation (standing anesthesia and nerve blockade such as the inferior alveolar nerve). The first step of the procedure is to reposition the fractured bone and tooth. Placement of the pins in the bone have to be done in an aseptic way and should be done very precisely under the control of X-ray examination to avoid damaging the roots of the teeth. In young horses, the molar and premolar teeth are quite long so the area where the implants can be inserted is really small. To mount the fixator on the mandible, only small four stab incisions have to be performed. Then, the radiographs are obtained, and the pin sites are chosen based on the relationship between the teeth roots and the fracture line. To drill holes in the bone, a $4.5 \mathrm{~mm}$ drill bit is used. During drilling, the sleeve should be used to protect the soft tissue. The drill bit has to be continuously flushed with a sterile isotonic solution as to avoid thermal injury to the bone. The holes are drilled through the bone (in both cortical parts). To provide better stabilization of the fracture, holes were created in an oblique way considering the surface of the bone. Two implants were inserted in each fragment of the bone through the tooth's cortical parts with a use a special key (3 in Figure 5). After implanting all four apex pins into the bone, the fixator is connected to the implants by using hexagonal keys ( 1 and 2 in Figure 5). The completely mounted stabilizer on the mandible can be seen in Figure 6. After fixing the stabilizer, single interrupted sutures are placed and a small bandage is applied to protect the parts of the stabilizer from interfering with the parts of the horse box, as well as preventing contamination (Figure 7). 


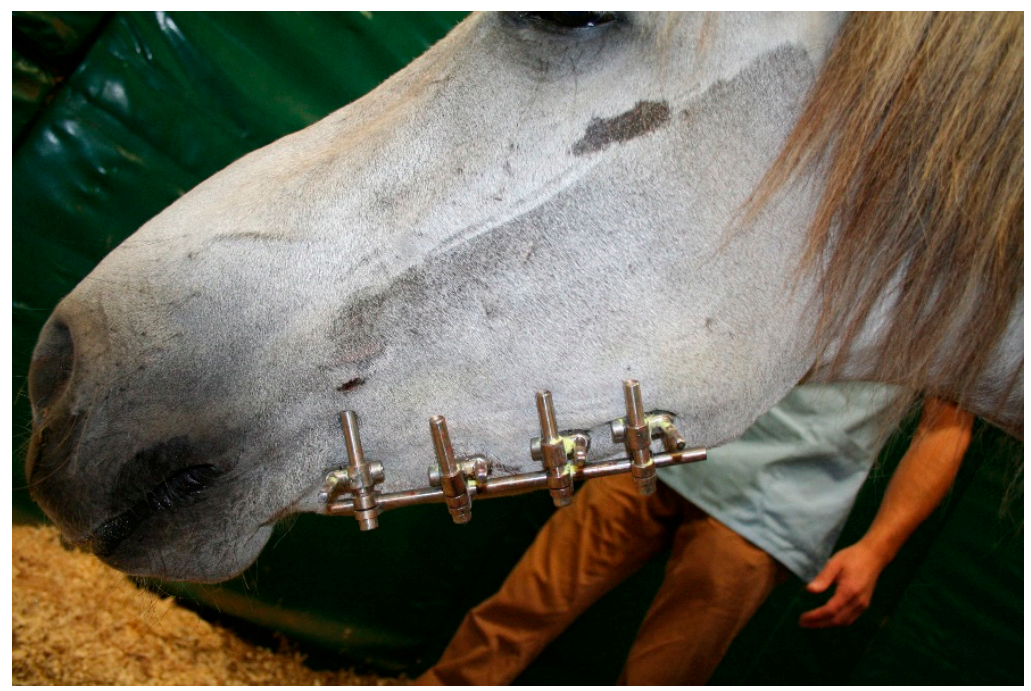

Figure 6. Equine head with unilateral external fixator used during the treatment of the mandible fracture.

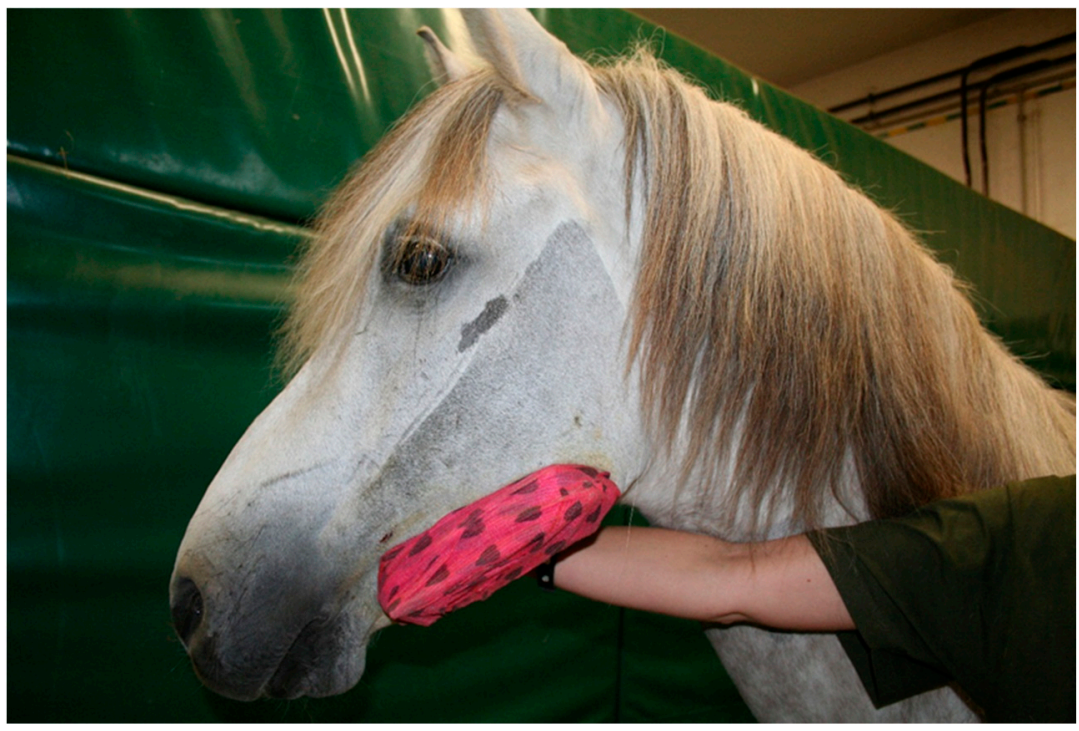

Figure 7. Equine head with unilateral external fixator protected by a bandage.

\section{Results}

The stabilizer of such design was made according to previously prepared drawings. Stainless-steel $1 \mathrm{H} 18 \mathrm{~N} 9 \mathrm{~T}$ was used to produce all elements of the stabilizer. Until now, the fixator has been used successfully in the treatment of selected open fractures in horses (Figure 6). Two cases involving fracture of the left mandibular body (adult horses) where the premolar and molar teeth were involved in the fracture line, and one case of comminuted tibial fracture in a four-month-old foal. A combination of cortical screws, fiberglass bandage, and external unilateral fixator were used for the latter.

The first case was a sport jumping horse. The stabilizer was removed after four weeks from surgery and the horse returned successfully to sport after four months.

In the second case (leisure sport horse), the fracture was more complicated because it was connected with comminuted tooth fracture. The stabilizer was removed after seven weeks from surgery. The problem in this case was the remaining fistula after treatment because the fractured tooth could not be removed straightforwardly. The decision to remove the tooth was made after six months-not earlier, as the tooth was needed to provide good stabilization during healing. Moreover, there was a significant risk of mandible fracture during the tooth extraction. The time for complete healing was seven months. 
In the third case (comminuted fracture of tibia), the stabilizer was removed 10 weeks after the surgery. The foal could walk, trot, and gallop three months after osteosynthesis. At the age of seven months, the foal joined the rest of the horses on the paddock, and after two years, the foal began racing. Due to the lack of significant results on the racing track, the owners changed the use of the horse to endurance riding, which yielded successful results.

\section{Discussion}

External fixators are valuable for the treatment of open and infected fractures involving the horizontal part of the mandible [5,8,9]. Like any other methods, external fixation has its advantages and disadvantages. The following advantages offered by this fixator can be distinguished: Easy application, easy removal, minor application- and removal-related tissue injury, small size that does not hinder everyday functioning of the patient (drinking and eating), and the possible use in open and infected fractures. This method ensures a good view of the wound and its possible treatment. General anesthesia is not necessary to remove implants from the bone, while the entire fixator can be removed in a stable, without the need to transport the patient to a clinic. The main rod, with arms and pin couplings, is mounted at some distance so that the fixation is not too rigid, which promotes the formation of abundant bone scarring.

On the other hand, the following disadvantages have to be taken into consideration: transmission of infection along the implants, and implant loosening. These phenomena are rather distinct after several weeks of treatment because this period of time is usually sufficient to achieve desired bone union.

Pinless external fixator (PEF) created by Swiss scientists has many advantages, like easy application, easy removal, minimal soft tissue trauma, but the biggest disadvantages are its large construction, high risk of unintended removal, and clamps loosening [8,9].

While attempting to design the fixator, the following requirements set for good fixators were taken into account:

1. Easy application - the time needed to place the fixator should be as short as possible, which is of great importance for the patient's safety. The longer the patient remains under anesthesia, the greater the risk of possible complications. In order to place the fixator, it is necessary to insert four implants into the bone and connect them with the fixator. Four holes with a diameter of $4.5 \mathrm{~mm}$ have to be drilled to insert pins into the bone. Thus, time and bone damage are not extensive. The use of an appropriate driller for this task makes it much easier. Due to self-tapping pins, there is no need to tap holes into the bone, which significantly shortens time. The fixator can be assembled in advance before the surgery so that time is saved at this stage. It is mounted with pins in a rather short time provided that appropriate assembly tools are available. In this case, application of special tools significantly reduces time to insert the pins and to place the fixator. Its elements are external to the bone, eliminating issues related to a small amount of soft tissue, which in turn, poses a challenge in case of plates use (difficulties with stitching the wound and hiding the plates under the skin). Surgery is conducted at a certain distance from the fracture site, therefore, reducing the risk of infection. Comparing the easy applications of other fixators, the PEF is the easiest one [8,9].

2. Easy removal-it is often more difficult to remove plates and screws than to place them due to bone scarring and lesions in the surrounding soft tissue. Removing the fixator and pins from the bones is very easy and quick. It is worth emphasizing that no general or local anesthesia is needed. At most, it may be necessary to sedate the patient as the sounds made by the tools may cause the horse to become anxious. Unscrewing the individual elements of the fixator is painless, similar to the removal of pins from bone. This is an important factor taken into account when deciding whether to start treatment. The ultimate cost is substantially reduced and, furthermore, the patient is not exposed to additional general anesthesia and the possible risks arising from it. The fixator may be successfully removed under field conditions without the need to transport the horse to the clinic. Often, horses sustain serious injuries during transport. 
3. Minor tissue injury related to both placement and removal. During insertion of the pins, care should be taken mainly in young animals to avoid damage to the roots of the teeth. Radiographs should be used to control proper placement.

4. Adjustable flexibility of fixation and possible correction during treatment. The fixator meets this requirement in all cases. There is a possibility of the individual arms and pin couplings becoming loose and more distant from each other. This may occur if there is abundant bone scarring formed, interfering with the fixator's elements. In this case, it is necessary to place the fixator further to treat the tibial fracture. Additionally, owing to the greater distance of pin couplings, the fixator becomes more flexible, which stimulates the formation of bone scarring at the fracture site. The flexibility was also increased due to the reduced diameter of the main rod from $10 \mathrm{~mm}$ to $8 \mathrm{~mm}$. This protects the bone from its destruction to a significant extent.

5. Low weight-a fixator should not become a great burden for the patient. This is an important feature that aids the patient's comfort with this device.

6. The fixator cannot hinder regular functioning of the patient-fixators are often so extensive that they are rejected by the patient as they substantially limit movement. In this case, it is mounted close to the body so that it does not affect regular functioning. Moreover, the fixator should not interfere with eating and drinking. A dressing that covers the fixator protects the wound against possible injuries, contamination, and infection. In addition, this permits good access to the operated area, and wound care is possible.

7. Easy access to the operated area and possible treatment of existing wound.

8. Good stabilization of bone fragments-being attached outside of the bone at some distance, the fixator is not as durable as plate fixations. If the fixator is placed at a larger distance from the bone, its durability decreases and its flexibility increases. It is not easy to achieve this goal as the fixator is placed at a certain distance from the bone.

The best stabilization can be provided by the placement of an LCP plate at the ventrolateral site of the mandible $[13,16,17]$. In this particular situation involving unilateral fracture, strong fixation is not needed. All molars and premolars have to be present to stabilize the fracture of the mandibular body. Therefore, even if they are broken, they should not be extracted when treatment is initiated but only when it is completed. Good stabilization may also be achieved if pin couplings are placed as close to the skin as possible. This is how the stress-transferring lever is shortened. In this case, pin couplings of a new type allowed us to place them as close to the patient as possible, thereby substantially increasing the fixator's durability. Threaded apex pins significantly reduce the risk of their loosening in the bone [24]. The investigation performed by some authors by coating the pins with hydroxyapatite showed increased pin stability within the third metacarpal bone but did not improve pin performance on clinical assessments [24]. The main reason for loosening the implants within the bone are problems with infection and big differences of the modulus of elasticity between the implants and bone [24]. During the treatment of open fractures, it is not possible to avoid infection. The second problem can be solved by using nickel-titanium alloys, which have relatively low stiffness (Young's modulus 1.8-14.7 GPa) compared to that for bone (17.6-31.2 GPa). Thus, they may be promising materials for producing new bone implants [25].

Flexibility of the fixation observed during treatment should be considered as beneficial for the patient, promoting the formation of more abundant bone scarring and better union [26,27]. The biomechanical properties of the fixator have not been investigated but we know from practice that the strength of the fixation is good enough for the fracture to heal. Similarly, PEF have not been tested for mechanical strength [8,9]. Our fixator presented in this article is a part of the stabilizer dedicated for MC III bone fracture treatment, which has been tested mechanically [23]. The tests proved that the fixation is strong enough to allow horses to stand up after surgery [22].

9. Possible use in treatment of various fractures-universal application. The presented fixator meets this requirement. Fixators of various sizes intended for horses can be constructed using the main rod of various lengths. Furthermore, it can be used to treat certain long-bone fractures as an additional 
support in conservative management. The presented fixator has been already used successfully for the treatment of comminuted tibial fracture in a four-month-old foal with the combination of cortical screws, fiberglass bandage, and external unilateral fixator.

10. As a spatial construction, it may also be used to treat opened fractures without the risk of transmitting infection-there is lack of direct contact of the fixator and implants at the fracture site.

Further studies are planned to investigate the acting forces during the treatment or during the testing of the osteotomized mandible when fixated by the stabilizer. The device is ready to use and is awaiting new patients with mandibular fractures (Figure 8).

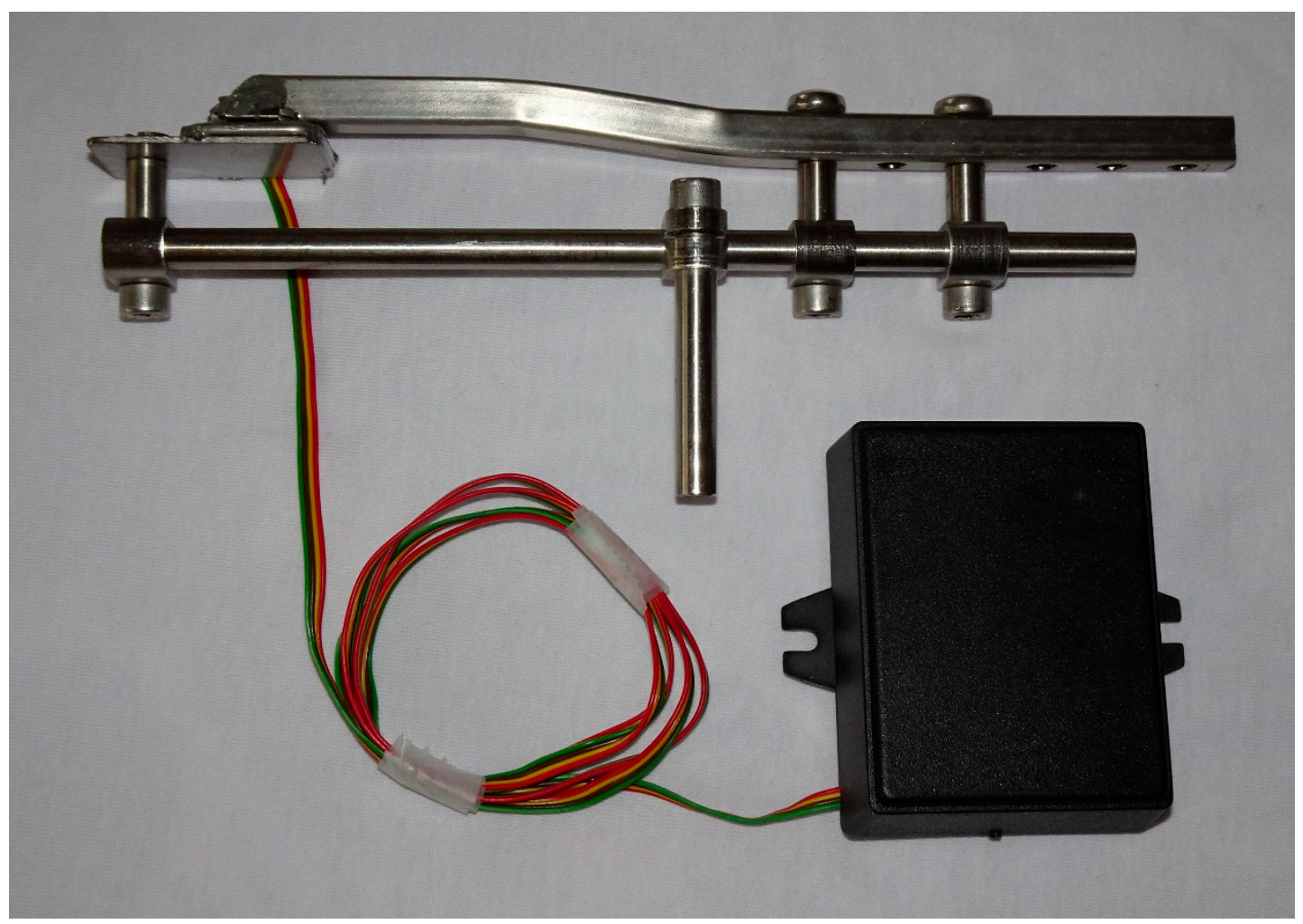

Figure 8. A deformation recording sensor attached to the special arm.

A deformation recording sensor with an accuracy of 10 micrometers in real time is attached to the special arm. The arm can be adapted to the current spacing. Information on deformation is transmitted via a cable to the central unit mounted on the animal, where data can be stored or transferred in real time to a PC via Bluetooth.

Knowledge about plasticity of the whole system obtained under laboratory conditions could transform the deformation of the set attached to the animal to the force generated for this deformation.

In the future, the construction of a device capable for recording forces in all dimensions is being explored.

\section{Conclusions}

We conclude that the presented unilateral external fixator can be a useful device for unilateral horizontal ramus fractures in horses. All parts of the fixator can be reused once again for the treatment of other cases. Also, pins are reusable but after several applications, it would be good to change them. The cost of new pins is really low.

Author Contributions: Conceptualization, B.T., Investigation, B.T., Methodology, B.T., M.K., Supervision, B.T., Writing—original draft, B.T., M.K., Writing-review \& editing, O.D.

Funding: This research received no external funding. 
Conflicts of Interest: The authors declare no conflict of interest.

\section{References}

1. Monin, T. Tension band repair of equine mandibular fractures. J. Equine Med. Surg. 1977, 1, 325-329.

2. DeBowes, R.M. Fractures of the mandible and maxilla. In Equine Fracture Repair, 1st ed.; Nixon, A.J., Ed.; W.B. Saunders Co.: Philadelphia, PA, USA, 1996; pp. 323-335.

3. Tremaine, W.H. Management of equine mandibular injuries. Equine Vet. Educ. 1998, 10, 146-154. [CrossRef]

4. Peavey, C.L.; Edward, R.B., III; Escarcega, A.J.; Vanderby, R., Jr.; Markel, M.D. Fixation technique influences the monotonic properties of equine mandibular fracture constructs. Vet. Surg. 2003, 32, 350-358. [CrossRef] [PubMed]

5. Belsito, K.A.; Fischer, A.T. External skeletal fixation in the management of equine mandibular fractures: 16 cases (1988-1998). Equine Vet. J. 2001, 33, 176-183. [CrossRef]

6. Widmer, A.; Fürst, A.; Bettschart, R.; Makara, M.; Geyer, H.; Kummer, M. Bilateral Iatrogenic Maxillary Fractures After Dental Treatment in Two Aged Horses. J. Vet. Dent. 2010, 3, 160-162. [CrossRef] [PubMed]

7. Jansson, N. Conservative Management of Unilateral Fractures of the Mandibular Rami in Horses. Vet. Surg. 2016, 45, 1063-1065. [CrossRef] [PubMed]

8. Haralambus, R.M.A.; Werren, C.; Brehm, W.; Tessier, C. Use of a Pinless External Fixator for Unilateral Mandibular Fracture Repair in nine Equids. Vet. Surg. 2010, 39, 761-764. [CrossRef] [PubMed]

9. Lischer, C.J.; Fluri, E.; Kaser-Hotz, B.; Bettschart-Wolfenberger, R.; Auer, J.A. Pinless external fixation of mandible fractures in cattle. Vet. Surg. 1997, 26, 14-19. [CrossRef]

10. Henninger, R.W.; Beard, W.L.; Schneider, R.K.; Bramlage, L.R.; Burkhardt, H.A. Fractures of the rostral portion of the mandible and maxilla in horses: 89 cases (1979-1997). J. Am. Vet. Med. Assoc. 1999, 214, 1648-1652.

11. Auer, J.A. Mandible, maxilla and skull. In AO Principles of Equine Ostheosynthesis; Fackelman, G.E., Auer, J.A., Nunamaker, D.M.N., Eds.; Thieme Verlag: Stuttgart, Germany, 2000; pp. 35-49.

12. Auer, J.A. Craniomaxillofacial disorders. In Equine Surgery, 3rd ed.; Auer, J.A., Stick, J.A., Eds.; Saunders Elsevier: St. Louis, MO, USA, 2006; pp. 1341-1362.

13. Kuemmerle, J.M.; Kummer, M.A.; Auer, J.A.; Nitzl, D.; Fürst, A.E. Locking compression plate osteosynthesis of complicated mandibular fractures in six horses. Vet. Comp. Orthop. Traumatol. 2009, 22, 54-58.

14. Kuemmerle, J.M. Mandibular fractures in horses. Equine Vet. Educ. 2012, 24, 222-224. [CrossRef]

15. Caldwell, F.J.; Davis, H.A. Surgical reconstruction of a severely comminuted mandibular fracture in a horse. Equine Vet. Educ. 2012, 24, 217-221. [CrossRef]

16. Beard, W. Fracture repair techniques for the equine mandible and maxilla. Equine Vet. Educ. 2009, 21, 352-357. [CrossRef]

17. Durket, E.; Kersh, K.; Dembek, K.; Riedesel, E.; Silverstone, A.; Kraus, K.H. Influence of plate type and placement on the immobilization of bilateral equine mandibular osteotomies: Ex vivo study. Vet. Surg. 2019, 1-6. [CrossRef] [PubMed]

18. Amerinatanzi, A.; Mehrabi, R.; Ibrahim, H.; Dehghan, A.; Moghaddam, N.S.; Elahinia, M. Predicting the Biodegradation of Magnesium Alloy Implants: Modeling, Parameter Identification, and Validation. Bioengineering 2018, 5, 105. [CrossRef] [PubMed]

19. Beste, K.; Glass, K.; Watkins, J. Intramedullary, Interlocking Nail Fixation Alone or in Combination with a Cranial Bone Plate to Repair Diaphyseal Femur Fractures in 16 Foals Weighing Less than 250 kg (1993-2016). Vet. Comp. Orthop. Traumatol. 2018, 31, A1-A25. [CrossRef]

20. Sisk, T.D. External fixation. Historic review, advantages, disadvantages, complications and indications. Clin. Orthop. Relat. Res. 1983, 180, 15-21.

21. Vogel, S.R.; Anderson, D.E. External Skeletal Fixation of Fractures in Cattle. Vet. Clin. Food Anim. 2014, 30, 127-142. [CrossRef]

22. Turek, B.; Potyński, A.; Wajler, C.; Szara, T.; Czopowicz, M.; Drewnowska, O. Biomechanical study in vitro on the use of self-designed external fixator in diaphyseal III metacarpal fractures in horses. Polish J. Vet. Sci. 2015, 18, 323-332. [CrossRef]

23. Turek, B.; Potyński, A.; Drewnowska, O. Own-design external fixator for the treatment of diaphyseal fractures of the third metacarpal bone in horses. Med. Weter. 2016, 72, 197-202. 
24. Lescun, T.B.; Baird, D.K.; Oliver, L.J.; Adams, S.B.; Hawkins, J.F.; Moore, G.E. Comparison of hydroxyapatite-coated and uncoated pins for transfixation casting in horses. Am. J. Vet. Res. 2012, 73, 724-734. [CrossRef] [PubMed]

25. Dehghanghadikolaei, A.; Ibrahim, H.; Amerinatanzi, A.; Ashemi, M.; Moghaddam, N.S.; Elahinia, M. Improving corrosion resistance of additively manufactured nickel-titanium biomedical devices by micro-arc oxidation process. J. Mater. Sci. 2019, 54, 7333-7355. [CrossRef]

26. Wagner, M. General principles for the clinical use of the LCP. Injury 2003, 34 (Suppl. 2), B31-B42. [CrossRef] [PubMed]

27. Auer, J.; Grainger, D. Fracture management in horses: Where have we been and where are we going? Vet. J. 2015, 206, 5-14. [CrossRef] [PubMed]

C 2019 by the authors. Licensee MDPI, Basel, Switzerland. This article is an open access article distributed under the terms and conditions of the Creative Commons Attribution (CC BY) license (http://creativecommons.org/licenses/by/4.0/). 